\title{
Role of Magnetic Resonance Imaging in Evaluation of Tubercular Spondylitis: Pattern of Disease in 100 Patients with Review of Literature
}

\author{
Khalid $M^{1}$, Siddiqui $M A^{1}$, Qaseem $S M D^{1}$, Mittal S', Iraqi $A A^{2}$, Rizvi SAA ${ }^{3}$ \\ 'Department of Radiodiagnosis, ${ }^{2}$ Department of Orthopaedics, ${ }^{3}$ Department of Surgery, Jawaharlal Nehru Medical College, \\ AMU Aligarh
}

\section{ABSTRACT}

Introduction: The purpose of this study is to evaluate the role of magnetic resonance imaging (MRI) in evaluation of tubercular spondylitis and to correlate imaging findings with clinical severity of the disease.

Methods: One hundred consecutive patients, who presented with features suggestive of spinal infections, were subjected to MRI examination. T1W and STIR images were obtained followed by T2W and post-contrast T1W images. Various imaging characteristics of spinal infections were noted and correlated with the clinical severity of the disease.

Results: Backache was the most common presenting symptom present in $86 \%$, while paraparesis was the most common sign seen in $62 \%$. The neurological status of the patients correlated well with MRI findings in the majority of the cases with an overall good correlation obtained in $96 \%$ of cases. The majority of the vertebrae and intervertebral discs affected showed hypointensity or isointensity on T1W images and hyperintensity on T2W images. Epidural/dural disease was present in $74 \%$ while $68 \%$ of patients demonstrated decreased intervertebral disc height. Epidural extension and subligamentous spread was in $74 \%$ and $90 \%$ of patients respectively.

Conclusions: MRI plays a vital role in early and accurate diagnosis of spinal infections. It is noninvasive and clearly demonstrates soft tissue anatomy and pathology which makes it superior to X-rays and Computed Tomography (CT). Imaging findings of tubercular spondylitis were also found to have a good correlation with the clinical status of the patients. Hence, it is of much help in the evaluation and assessment of patients presenting with features of spinal infections.

Keywords: Magnetic resonance imaging, spinal tuberculosis, tubercular spondylitis

\section{INTRODUCTION}

The spine is affected by a number of infections, with tubercular and pyogenic ones being the commonest. The rising incidence of tubercular infection and the related morbidity and mortality calls for an accurate diagnosis. ${ }^{1,2}$ As tubercular infection is characterized by an insidious onset, delay in diagnosis resulting in serious neurological complications is not uncommon. ${ }^{2}$ The definite diagnosis is best established by combining radiological imaging with clinical findings. MR imaging is the modality of choice in spinal infections as it is noninvasive and clearly demonstrates soft tissue anatomy, including spinal cord or nerve root involvement ${ }^{2,3}$. This study attempts to assess the role of MRI imaging in

\footnotetext{
Correspondence:

Dr. Mohammed Azfar Siddiqui

Department of Radiodiagnosis,

Jawaharlal Nehru Medical College,

AMU Aligarh [U.P.]- 202002

Telephone (m)- 0091-9719361454
} 
tubercular spondylitis and to correlate the imaging findings with the clinical severity of the disease.

\section{METHODS}

This prospective observational study was conducted in the department of Radiodiagnosis, Jawaharlal Nehru Medical College Hospital (JNMCH), AMU, Aligarh, over a span of 18 months, from September 2008 to February 2010. The study was approved by the ethical committee of the hospital and written and informed consent was taken from the patients/attendants. A total of 137 patients presenting with signs and symptoms consistent with spinal infections, i.e., fever, backache, radicular pain, paraparesis or quadriparesis, were included in study. Of the 137, 33 patients were later diagnosed as having pyogenic spondylitis and were excluded from the study. Four patients were lost in the follow-up. The final analysis included 100 patients with the final diagnosis of tuberculous spondylitis. Clinical evaluation of all cases and assessment of the need for MRI was done. The cases were taken up for MR within 72 hours of presentation. Cases fulfilling the following criteria were included in the study:-

1) Patients presenting with clinical feature suggestive of spinal infections as described above with or without radiographic abnormality.

2) Cases where MRI could be done within 72 hours of presentation.

3) Patients in whom pathological confirmation of tuberculosis could be done or where clinical followup showed positive response to anti-tubercular treatment.

Patients were excluded from the study based on following exclusion criteria:-

1) Patients who had received some treatment before admission.

2) Patients who had pyogenic infection.

3) Patients who had infection secondary to trauma

4) Patients lost to follow-up.

5) Uncooperative patients, like same paediatric patients, and those requiring anaesthesia.

6) Patients with general contraindications to MRI examination, like those with claustrophobia, metallic implants, pacemakers or indwelling catheter.

Patients were classified into four grades based on the following classification system proposed by Tuli $\mathrm{SM} .{ }^{4} \mathrm{~A}$ Grade I patient is unaware of any neurological deficit. Clinical examination detects positive Babinski sign and ankle or patellar clonus. A Grade II patient presents with complaints of clumsiness, incoordination or spasticity while walking but manages to walk with or without support. A Grade III patient is not able to walk because of severe weakness. On examination, paraplegia in extension is seen. There may be partial loss of sensation. A Grade IV patient is unable to walk and has paraplegia in flexion with severe muscle spasm. There is near complete loss of sensation with sphincter disturbances. We have classified Grade I and II paraplegia as mild, Grade III as moderate and Grade IV as severe.

The MRI investigations were done on SIEMENS MAGNETOM AVANTO 1.5 Tesla system using the matrix size of 256/256, slice thickness 3 - $4 \mathrm{~mm}$ and intersection gap $10 \mathrm{~mm}$. Finer sections and postcontrast sequences using intravenous gadolinium diethylenetriaminepentaacetic acid (DTPA)[0.2mmol/ $\mathrm{kg}$ ] were obtained wherever necessary. The following sequences were obtained:-

1. T1 weighted sagittal fast spin echo (FSE) (Time to repeat (TR)/Time to echo (TE)-580/12, Field of view $30-35 \mathrm{~cm})$;

2. T2 weighted sagittal FSE (TR/TE-4000/102, Field of view30-35cm);

3. T1 weighted axial FSE (TR/TE-594/15, Field of view15-20cm);

4. T2weighted axial FSE (TR/TE-4000/99, Field of view $15-20 \mathrm{~cm})$;

5. T1 weighted STIR coronal (TR/TE-3500/37, TI 160, Field of view $24-30 \mathrm{~cm})$;

6. Post contrast T1 weighted STIR sagittal, coronal and axial sequences.

\section{The following parameters were noted in the image} analysis:-

1. Presence of epidural/dural disease.

2. Degree of spinal cord/nerve root compression.

3. Site of spinal infection-cervical/thoracic/lumbar/ sacral.

4. Intervertebral disc attributes- disc height, signal intensity on T1 and T2 weighted imaging and presence of contrast enhancement.

5. Vertebral attributes- signal intensity on T1 and T2 weighted imaging and presence of contrast enhancement.

6. Status of endplates, presence of vertebral collapse and kyphosis, affliction of multiple vertebrae $(>3)$.

7. Involvement of posterior elements, presence of canal stenosis.

8. Presence of paraspinal abscess, its morphology, and 
presence of subligamentous spread.

9. Miscellaneous attributes-spinal cord changes, coincidental findings.

Confirmation of the diagnosis of tubercular spondylitis was based on

1. Culture growth or characteristic histological changes of infection in biopsy.

2. Positive response to anti-tubercular treatment.

Out of 100 patients, biopsy was done in 34 patients while in 66 patients, the diagnosis of tubercular spondylitis was made based on positive response to anti-tubercular treatment. The biopsy in most cases was done after the MRI.

The statistical analysis was done by Microsoft excel 2007 and statistical package for social sciences (SPSS) software.

\section{RESULTS}

A total of 100 patients, 54 females and 46 males, who presented with features suggestive of spinal infections were evaluated with MR study of the spine over a period of 18 months.

The disease was maximally seen in the younger age group with 22 males and 20 females being less than 30 years. The majority of patients $(52 \%)$ presented with a 4 - 8 months of disease duration. The next common duration was $0-3$ months seen in 30 cases $(30 \%)$. The minimum duration of presentation was about 1 month and the maximum about 3 years.

The thoracic spine was the most common region to be affected and was seen in 48 cases (48\%). This was followed by the lumbar spine ( $26 \%$ ) and thoracolumbar (6\%) region. No disease was documented in the sacral region.

The most common presenting symptom (Table 1) in our patients was backache, being present in $86(86$ $\%)$ patients, followed by radicular pain in 84 (84 \%) patients, fever in $48(48 \%)$ patients and constitutional symptoms in 42 (42\%) patients. The least common presenting symptom was seizure being present in only 2 ( $2 \%$ ) patients. The most common presenting sign in our study was paraparesis in 62 (62\%) patients followed by spinal tenderness in 54 (54\%) patients. Kyphosis and bladder or bowel incontinence was present in 18 (18\%) patients each. The least common presenting sign was quadriparesis noted in $2(2 \%)$ patients.
The proportion of cases (Table 1) having erosion of end plates, vertebral body collapse, kyphosis and multiple vertebral body afflictions was seen in 98 (98\%), 62 (62 \%), 52 (52\%) and 50 (50\%) patients respectively. Posterior element involvement was present in 86186 $\%)$ cases and canal stenosis was present in about $70(70 \%)$ cases. Epidural extension was seen in 74 (74\%) patients and subligamentous spread in 90190 $\%)$. Seventy four (74 \%) had epidural/dural disease. Paraspinal abscess was present in 92 (92 \%) cases, most of which showed a smooth wall (90\%). However, the abscess was irregular in $10 \%$ of cases. A rim pattern of enhancement was seen in all cases.

Table 1: Clinical features and various MRI features

\begin{tabular}{|c|c|c|}
\hline & $\begin{array}{l}\text { No. of } \\
\text { Patients } \mathrm{n} \\
=100\end{array}$ & Percent \\
\hline Symptoms: & & \\
\hline $\begin{array}{l}\text { Back ache } \\
\text { Radicular Pain } \\
\text { Fever } \\
\text { Constitutional } \\
\text { Symptoms } \\
\text { Seizure }\end{array}$ & $\begin{array}{c}86 \\
84 \\
48 \\
42 \\
2\end{array}$ & $\begin{array}{c}86 \% \\
84 \% \\
48 \% \\
42 \% \\
2 \%\end{array}$ \\
\hline Signs: & & \\
\hline $\begin{array}{l}\text { Paraparesis } \\
\text { Spinal Tenderness } \\
\text { Kyphosis } \\
\text { Bladder - Bowel } \\
\text { Incontinence } \\
\text { Quadriparesis }\end{array}$ & $\begin{array}{l}62 \\
54 \\
18 \\
18 \\
\\
2\end{array}$ & $\begin{array}{l}62 \% \\
54 \% \\
18 \% \\
18 \% \\
2 \% \\
\end{array}$ \\
\hline Spinal cord compression & & \\
\hline $\begin{array}{l}\text { Mild } \\
\text { Moderate } \\
\text { Severe }\end{array}$ & $\begin{array}{l}26 \\
56 \\
18\end{array}$ & $\begin{array}{l}26 \% \\
56 \% \\
18 \%\end{array}$ \\
\hline Epidural/dural disease & 74 & 74 \\
\hline $\begin{array}{l}\text { Vertebral morphological attributes } \\
\text { End plate erosion } \\
\text { Vertebral collapse } \\
\text { Kyphosis } \\
\text { Multiple vertebrae } \\
\text { Posterior element } \\
\text { Canal stenosis }\end{array}$ & $\begin{array}{l}98 \\
62 \\
52 \\
50 \\
86 \\
70\end{array}$ & $\begin{array}{l}98 \% \\
62 \% \\
52 \% \\
50 \% \\
86 \% \\
70 \%\end{array}$ \\
\hline \multicolumn{3}{|l|}{ Soft tissue attributes } \\
\hline $\begin{array}{l}\text { Paraspinal abscess } \\
\text { Epidural extension } \\
\text { Subligamentous spread }\end{array}$ & $\begin{array}{l}92 \\
74 \\
90\end{array}$ & $\begin{array}{l}92 \% \\
74 \% \\
90 \%\end{array}$ \\
\hline
\end{tabular}

Spinal cord compression was of moderate grade of severity in the majority of cases, i.e., 56 (56\%) patients, 
while severe grade of compression was seen in 18 (18 $\%)$ cases. A mild degree of spinal cord compression was present in $26(26 \%)$ patients.

A total of 242 vertebrae were affected (Table 2). The majority of vertebrae, i.e, 120 (50 \%) showed a hypointense signal on T1 weighted images while 102 vertebrae (42\%) appeared isointense. On T2 weighted imaging the majority of vertebrae, i.e 230 (95 \%), appeared hyperintense. Contrast enhancement was seen in 228 vertebrae (94\%).

Table 2: MR signal intensity alteration in vertebrae and intervertebral discs

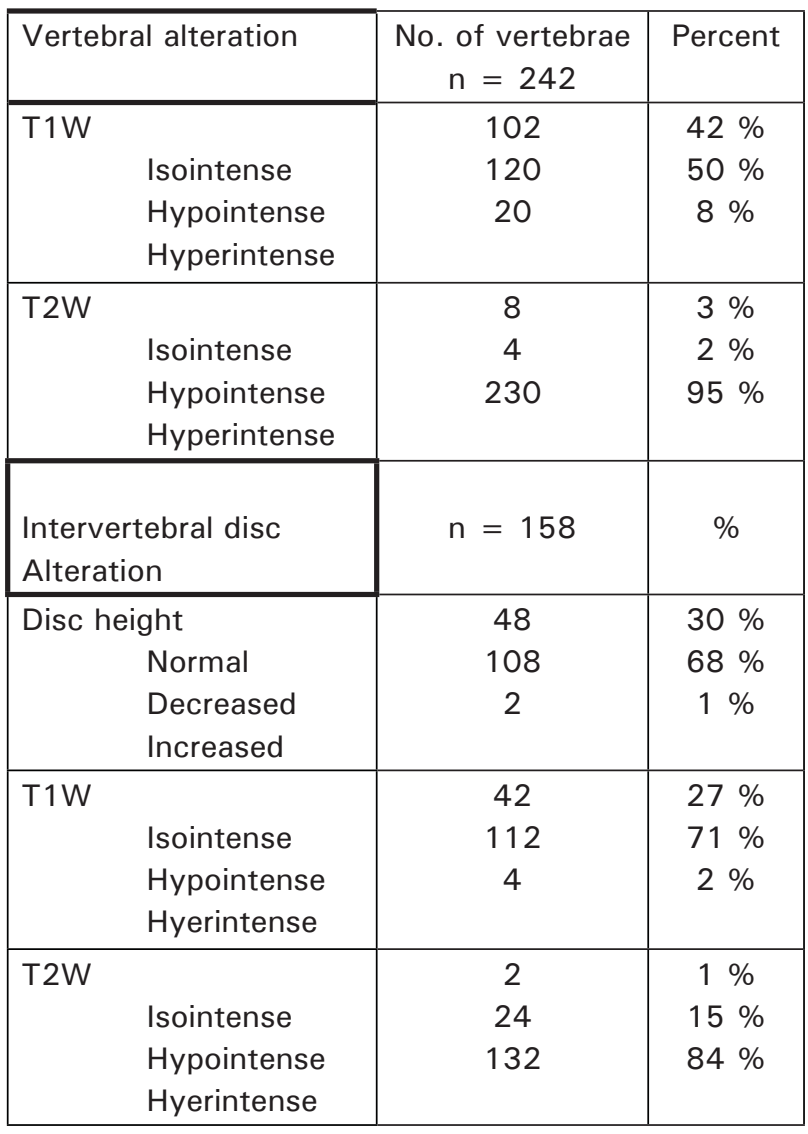

Also, a total of 158 intervertebral discs were affected (Table 2). Decreased intervertebral disc height was observed in 108 discs (68\%), whereas it was normal in 48 discs $(30 \%)$. Two discs (1\%) demonstrated an increased height. One hundred and twelve discs (71 \%) appeared hypointense on $\mathrm{T} 1 \mathrm{~W}$; and the next most common pattern was that of isointensity seen in 42 discs $(27 \%)$. On T2W images, the most common pattern was hyperintensity of infected discs and was observed in 132 discs (84\%). A much lower incidence was that of hypointensity seen only in 24 discs (15\%). Isointensity on T2W was rare, present in only 2 disc (1 $\%)$. Contrast enhancement was seen in 108 discs $(68$
$\%)$, however, 42 (31\%) of the discs did not enhance. A rim pattern of contrast enhancement was observed in all but one case.

Considering the neurological status of the patients (Table 3), mild neurological status correlated well with MR findings in $75 \%$ of cases. Similarly, regarding moderate clinical status, MR findings correlated in 92 $\%$ of cases. With severe clinical status, MR findings correlated well in $77 \%$ of cases. Overall a good correlation was obtained in $96 \%$ of cases.

Table 3: Correlation of neurological status with MR

findings

\begin{tabular}{|c|c|c|c|c|}
\hline MR & \multicolumn{3}{|c|}{ Clinical Severity } & \multirow{6}{*}{$\begin{array}{c}\text { Overall } \\
\text { good } \\
\text { correlation } \\
\text { obtained } \\
\text { in } 96 \% \\
\text { of cases }\end{array}$} \\
\hline & $\begin{array}{c}\text { Mild } \\
n=32\end{array}$ & $\begin{array}{c}\text { Moderate } \\
\mathrm{n}=50\end{array}$ & $\begin{array}{c}\text { Severe } \\
(\mathrm{n}= \\
18)\end{array}$ & \\
\hline $\begin{array}{c}\text { Mild }(\mathrm{n}= \\
26)\end{array}$ & 24 & 2 & 0 & \\
\hline $\begin{array}{c}\text { Moderate } \\
(n-56)\end{array}$ & 6 & 46 & 4 & \\
\hline $\begin{array}{l}\text { Severe }(\mathrm{n} \\
=18)\end{array}$ & 2 & 2 & 14 & \\
\hline $\begin{array}{l}\text { Findings } \\
\text { correspond } \\
\text { in }\end{array}$ & $\begin{array}{c}75 \\
\% \text { of } \\
\text { cases }\end{array}$ & $\begin{array}{c}92 \% \text { of } \\
\text { cases }\end{array}$ & $\begin{array}{c}77 \\
\% \text { of } \\
\text { cases }\end{array}$ & \\
\hline
\end{tabular}

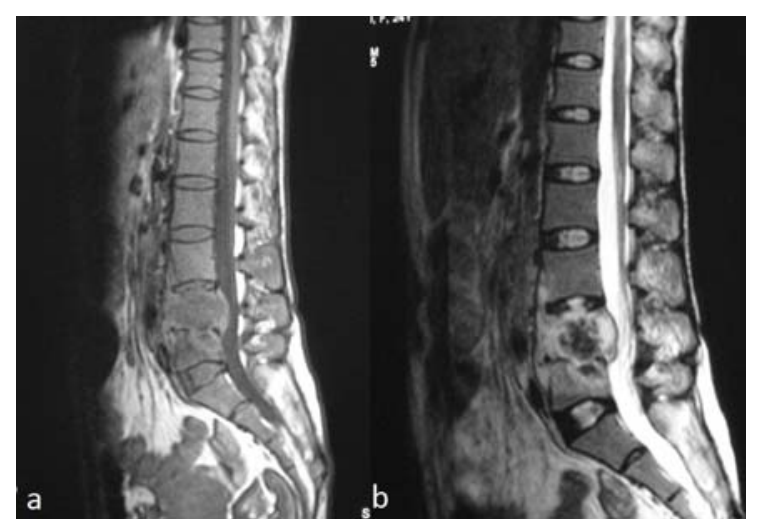

Figure 1. T1W (a) and T2W (b) sagittal MR images of lumbar spine demonstrates altered signal intensity of L4 and L5 vertebral bodies with loss of intervening intervertebral disc space. Evidence of intraosseous abscess, sub ligamentous spread and posterior extension into extradural spinal canal with narrowing of the thecal sac is also seen. 


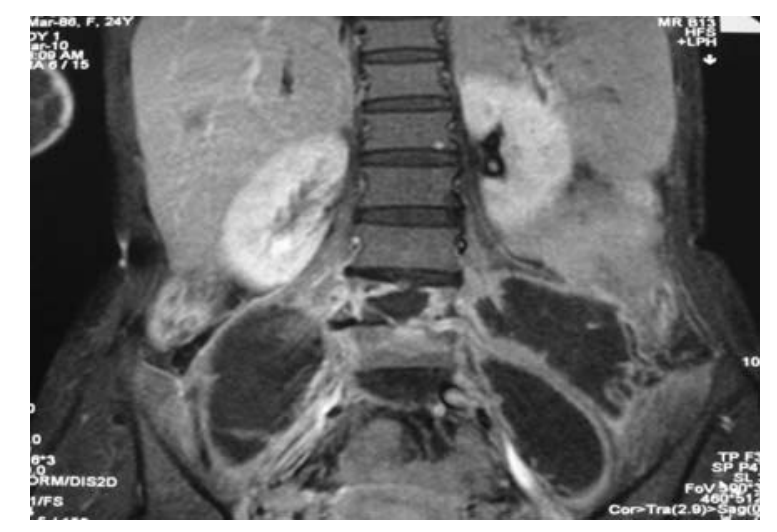

Figure 2. Post contrast TIW coronal MR image shows peripherally enhancing lesion in bilateral psoas muscle suggestive of psoas abscess.

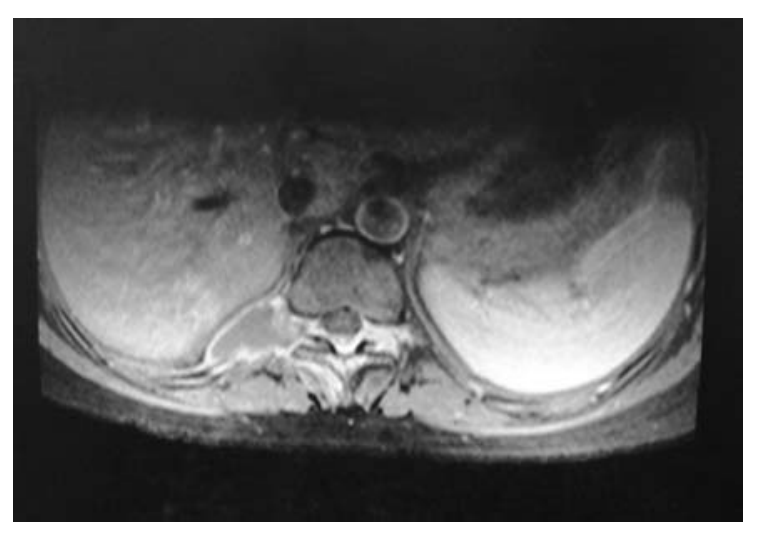

Figure 3. Post contrast T1W axial demonstrates peripherally enhancing right paravertebral lesion with involvement of ipsilateral posterior element, neural foramina and adjacent ribs.

\section{DISCUSSION}

In the present study, the male to female ratio was found to be 1:1.2, with $46 \%$ males and $54 \%$ females. Desai SS et $\mathrm{al}^{5}$ reported a similar distribution in their study. Backache was found to be the most common presenting symptom (86 \%cases). Radiculopathy was an accompanying symptom in $84 \%$ of cases. Paraparesis was the most frequent sign $162 \%$ of cases), followed by spinal tenderness (54\% of cases). These findings corroborated with those of Alothman A et $\mathrm{al}^{6}$ except for the higher incidence of paraparesis in our study. Features of cervical spine involvement like quadriparesis were seen in $2 \%$ of cases, pointing towards the rarity of cervical spine affliction. Most of the patients (52\%) had a 4 - 8 months duration of symptoms which is in accordance with the work of Smith AS et al $^{7}$.

Clinically, Grade 1 and 2 paraplegia was classified as mild, Grade 3 as moderate and Grade 4 as severe. Most cases $(50 \%)$ were of moderate clinical severity. The MR findings of neurological severity were the amount of spinal cord/nerve root compression and presence of epidural/dural disease. In $56 \%$ of cases, a moderate amount of spinal cord compression was observed while mild and severe in $26 \%$ and $18 \%$ cases respectively. A correlation between the MR findings and clinical neurological severity was obtained in $96 \%$ of cases. Sharif $\mathrm{HS}^{8}$ obtained similar results. In their study, the MRI findings and neurological status correlated in 93 $\%$ of cases.

The most common site of tubercular spondylitis was thoracic spine (48\%) followed by the lumbar (26\%) and thoracolumbar $(6 \%)$ regions. Alothman $A$ et $\mathrm{al}^{6}$ also found the thoracic spine as the most common site, present in $55 \%$ of cases of their study.

A decreased disc height on MRI, a finding suggestive of spinal infection, was seen in $68 \%$ of cases. Jung $\mathrm{NY}$ et $\mathrm{a}^{9}$ also reported similar findings with a decreased height seen in $55 \%$ of cases. A hypointensity was observed in the intervertebral discs on T1W imaging (71 \%) and hyperintensity on T2W imaging (84\%), which correlates with the observations of Ledermann $\mathrm{HP}$ et $\mathrm{al}^{10}$ andDanchaivijitra $\mathrm{N}$ et $\mathrm{al}^{11}$. Contrast enhancement of the intervertebral disc was seen in $68 \%$. The majority of cases showed a rim pattern of enhancement. The affected vertebrae showed hypointensity on T1W (50\%), hyperintensity on T2W $(95 \%)$ and rim pattern of contrast enhancement $(94$ $\%)$. Endplate disruption was seen in $98 \%$ of cases while vertebral collapse was noted in $62 \%$ of cases. Resultant kyphosis was also more common in tubercular cases. Paraspinal abscess was seen in 92 cases 192 $\%)$. The abscess had a smooth and regular wall in 90 $\%$ of cases and demonstrated rim enhancement in all cases. These findings were supported by the work of Jain $\mathrm{R}$ et $\mathrm{al}^{12}$ and Jung $\mathrm{NY}$ et $\mathrm{al}^{9}$. Enhancement of the anterior and posterior longitudinal ligament indicates subligamentous spread and was common in tubercular spondylitis. Epidural extension was seen in $74 \%$. Jain $R$ et $a^{12}$ found epidural extension in $66 \%$ of cases. Gadolinium DTPA images showed some important features of tubercular spondylodiscitis, like intraosseus and rim abscess, involvement of ligaments and dura and subligamentous spread, which cannot be obtained with $\mathrm{T} 1$ or $\mathrm{T} 2$ weighted imaging.

The overall sensitivity and specificity of the MRI for diagnosis of spinal tubercular infections was $97 \%$ and $80 \%$. Danchaivijitra $\mathrm{N}$ et $\mathrm{al}^{11}$ also supported this observation. In their study, the sensitivity and specificity of MRI for spinal tuberculosis were $100 \%$ and $88.2 \%$ respectively. 
In the last decade, many authors including Jung et $\mathrm{al}^{8}$, Harada et $\mathrm{al}^{13}$ and Chang et al ${ }^{14}$ have tried to determine the accuracy of MRI for discrimination between tuberculous spondylitis and pyogenic spondylitis. In there study, Jung et al found a sensitivity of $100 \%$ and specificity of $80 \%$ in identifying tuberculous spondylitis. They also suggested that MRI finding of a well-defined paraspinal abnormal signal, a thin and smooth abscess wall, paraspinal or intraosseous abscess, extensive subligamentous spread, and multiple vertebral bodies involvement have significantly higher incidence in patients with tuberculous spondylitis than in those with pyogenic spondylitis.

\section{CONCLUSIONS}

MR plays a vital role in early and accurate diagnosis of spinal infections because of its ability to delineate soft tissue anatomy and pathology in addition to bony involvement giving it an edge over CT and plain X-Ray. MR findings suggestive of tubercular spondylodiscitis as mentioned in this study are quite sensitive to disease and also point towards the etiology of infection with good sensitivity and specificity. These findings have a good correlation with clinical severity. Hence, an indirect assessment of neurological severity can be done. Thus, MR imaging should be used as the modality of choice for evaluation and assessment of patients with features of spinal infections.

\section{REFERENCES}

1. Wang D. Diagnosis of tuberculous vertebral osteomyelitis (TVO) in a developed country and literature review. Spinal Cord. 2005 Sep;43(9):531-42.

2. Jevtic V. Vertebral infection. Eur Radiol. 2004 Mar;14 Suppl 3:E43-52.

3. Andronikou S, Jadwat S, Douis H. Patterns of disease on MRI in 53 children with tuberculous spondylitis and the role of gadolinium. Pediatr Radiol. 2002 Nov;32(11):798-805.

4. Tuli SM. Judicious management of tuberculosis of bones, joints and spine. Ind J Orthop. 1985 Jul; 19: 147-166.

5. Desai SS. Early diagnosis of spinal tuberculosis by MRI. J Bone Joint Surg Br. 1994 Nov;76(6):863-9.

6. Alothman A, Memish ZA, Awada A, Al-Mahmood S, AlSadoon S, Rahman MM, et al. Tuberculous spondylitis: analysis of 69 cases from Saudi Arabia. Spine (Phila Pa 1976). 2001 Dec 15;26(24):E565-70.

7. Smith AS, BlaserSI . Infectious and inflammatory process of the spine. Radiol Clin North Am. 1991 Jul;29(4): 809-27.
8. Sharif HS. Role of MR imaging in the management of spinal infections. Am J Roentgenol. 1992 Jun;158(6):1333-45.

9. Jung NY, Jee WH, Ha KY, Park CK, Byun JY. Discrimination of tuberculous spondylitis from pyogenic spondylitis on MRI. Am J Roentgenol. 2004 Jun;182(6):1405-10.

10. Ledermann HP, Schweitzer ME, Morrison WB, Carrino JA. MR Imaging findings in spinal infections: rules or myths. Radiology. 2003 Aug; 228:506-514.

11. Danchaivijitr N, Temram S, Thepmongkhol K, Chiewvit P. Diagnostic accuracy of MR Imaging in tuberculous spondylitis. J Med Assoc Thai. 2007 Aug;90(8):1581-9.

12. Jain R, Sawhney S, Berry M. Computed tomography of vertebral tuberculosis: patterns of bone destruction. Clin Radiol. 1993 Mar;47(3):196-9.

13. Harada $Y$, Tokuda $O$, Matsunaga N. Magnetic resonance imaging characteristics of tuberculous spondylitis Vs. pyogenic spondylitis. Clin Imaging. 2008 Jul-Aug;32(4):303-9.

14. Chang MC, Wu HT, Lee CH, Liu CL, Chen TH. Tuberculous spondylitis and pyogenic spondylitis: comparative magnetic resonance imaging features. Spine (Phila Pa 1976). 2006 Apr 1;31(7):782-8. 